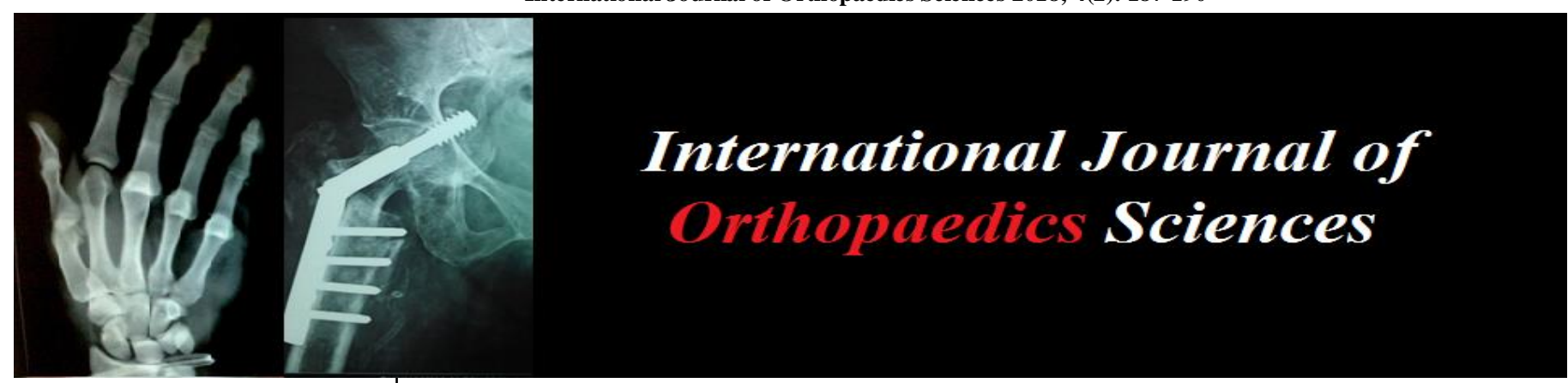

ISSN: $2395-1958$

IJOS 2018; 4(2): 187-190

(C) 2018 IJOS

www.orthopaper.com

Received: 20-02-2018

Accepted: 21-04-2018

Dr. Chandra Prakash Singh

Associate Professor,

Department of Orthopedics,

Saraswathi Institute of Medical

Sciences, Anwarpur, Pilkhuwa,

Hapur, U.P, India

\section{A clinical study on analysis in mid shaft femur fractures with the application of intramedullary nail}

\section{Dr. Chandra Prakash Singh}

DOI: https://doi.org/10.22271/ortho.2018.v4.i2c.2625

\section{Abstract}

Background: Femoral shaft fractures are usually the result of high- energy trauma, such as road traffic accidents. Kuntscher was the first to introduce the concept of intramedullary nailing, later there were modifications in intramedullary nailing and for the first time Klemm and Schelmann, Grosse and Kempt and Russel Taylor developed proximal and distal fixation called intramedullary interlocking nail. Intramedullary nailing provide predictable restoration of femoral shaft alignment along with load sharing. Aim and Objective: To evaluate an analysis in mid shaft femur fractures with the application of intramedullary nail.

Methodology: 37 cases of fracture shaft femur were studied in our study, admitted to A tertiary care teaching hospital in North India. All patients sustained a road traffic accident. Patient were analysed for short term outcome.

Results: The poor result in open interlocking nailing attributed to disturbance of fracture haematoma and periosteal stripping in open interlocking nailing. 3 patients had ipsilateral tibial shaft fracture 1 patient had degloving injury over his right calf region, 1 patient had ipsilateral patella and proximal third tibial fracture. All patients were investigated according to the protocol and surgery performed between day 3 to day 7 after trauma, average duration was 6 days. Blood loss ranged from 150-300ml with a mean of $200 \mathrm{ml}$.

Keywords: ipsilateral farctures, mid shaft femur fractures, intramedullary nail

\section{Introduction}

Most femoral shaft fractures are treated surgically. Several studies have indicated that early surgical stabilisation is associated with a reduction of complications and mortality. An intramedullary nail is a metal rod that is inserted into the medullary cavity of a bone and across the fracture in order to provide a solid support for the fractured bone. Intramedullary nailing is currently considered the "gold standard" for treatment of femoral shaft fractures. Proposed advantages of intramedullary nailing include short hospital- stay, rapid union of the fracture and early functional use of the limb. Femur is the largest bone of the body and one of the principal load bearing bones in lower extremity. Fracture of the shaft of femur are major cause of morbidity and mortality in patients ${ }^{[1]}$. Fracture of the shaft are the result of high energy trauma, which may be associated with multisystem injury and considerable soft tissue injury ${ }^{[2}$, ${ }^{3]}$. Fractures of the shaft in elderly patients in due to osteoporosis and trivial trauma [4, 5] Fractures of femur shaft may be predisposed due to pathological conditions of the femur ${ }^{[6]}$. Urgent prompt reduction and rigid stable internal fixation is todays accepted mode of treatment which will reduce the risk of pathophysiological complications as well as help to prevent permanent impairment of knee function by early mobilization. The method that is closely approaching this perfection is intramedullary interlocking nailing of femoral shaft fractures ${ }^{[1]}$. Thus intramedullary interlocking nailing has been the gold standard for treatment of facture shaft of femur, and hence, early mobilization, minimal scarring of thigh muscles and early recovery of quadriceps and hamstring function. The physiological loading condition of femur by muscular and gravitational forces are also favourable for intramedullary fixation. Intramedullary nailing aims to preserve the anatomical structure of fracture sites and to provide a proper environment for fracture healing. This in turn should improve function and reduce long- term complications such as pain from arthritis.
Dr. Chandra Prakash Singh Associate Professor, Department of Orthopedics, Saraswathi Institute of Medical Sciences, Anwarpur, Pilkhuwa, Hapur, U.P, India 
Furthermore, nailing helps to limit the damage to the soft tissues in the vicinity of bone during surgery and thereby helps preserve the blood supply to allow fracture healing and obtain a good functional recovery.

\section{Material and Methods}

This is a prospective study of 37 cases of unstable fractures of the femur, treated in the

Department of Orthopedics, A tertiary care teaching hospital in North India with closed reamed intramedullary interlocking nail.

\section{Inclusion Criteria}

1. Transverse, short oblique, communited, segmental fractures at the level of isthmus in adults.

2. Polytrauma patients where early mobilization is indicated

3. Failure to maintain reduction by conservative method.

4. Soft tissue interposition causing failure of reduction despite repeated manipulations.

5. Fracture involving upper or lower third of femur.

6. Fracture associated with head injury or paraplegia to aid constant turning of patient in bed.

7. Patients with age group of 18-65 years of either sex.

\section{Exclusion Criteria}

1. Type I, II, III compound or open fracture, because the danger of infection is too great.

2. Damaged or infected skin and soft tissue surrounding the fracture.

3. Poor anaesthetic risk. 4. Pre-existing deformity of femur from any disease.

4. Metaphyseal and intra articular fractures.

5. Delayed union, malunion and non-union cases

These cases of unstable fracture shaft femur were treated by femur interlocking nail, which is locally available and is based on AO design nail with proximal locking jig and two proximal and distal holes and one oblique proximal locking hole. The study was approved by the Ethical

Committee of the Medical College All patients of unstable fracture shaft femur attended at the department of Orthopaedics were studied. A detailed history was taken of these patients and was explained about the investigations and study. Detailed history was taken about age, sex, occupation, mode of injury, past history and associated medical illness. Thorough clinical examination and general condition was assessed. X-rays are taken in 2 planes, AP and lateral including X-ray of ipsilateral hip and knee joints. All the fractures were classified according to AO classification. Preoperatively the length of nail was measured clinically and radiographically.

Routine preoperative investigation assessment was done. Patients were operated under regional or general anesthesia after pre operative assessment. IV antibiotic was given $30 \mathrm{~min}$ before surgery. Oblique skin incision from the proximal tip of the greater trochanter taken and continued it proximally and poster-medially for $6-8 \mathrm{~cm}$. Piriformis fossa was palpated. Entry point was made with curved pointed awl and medullary cavity was perforated at piriformis fossa, after confirming under image intensifier. A guide wire was passed through the proximal fragment and under C-arm control. The fracture was reduced and guide wire was passed in to the distal fragment. If reduction was not possible by closed means then fracture site was opened through lateral incision and open was reduction done. The position was confirmed under the image intensifier in AP and lateral plane and tip of guide wire was hammered in to the subchondral bone. Reaming was done. Reaming was performed in $0.5 \mathrm{~mm}$ increments up to $1 \mathrm{~mm}$ diameter larger than the chosen nail to make nail passage easier. Distal locking Was done with a free hand technique and using $\mathrm{C}$-arm. Proximal locking was done with the help of proximal jig. Finally the whole length of the nail, reduction, proximal, and distal locking screws were checked under image intensifier. Open technique is necessary When close technique fails to reduce fracture fragments due to tissue interposition and acting muscular forces. For example in broken implant cases, Inability to pass guide wire in distal fragment and Cases operated more than 3 weeks after injury Postoperative care taken as follows Day 1: Early active flexion and extension are essential and encouraged. Day 2: Isometric and range of motion exercises begun Day 3: Gait training progressed from use of parallel bars to a walker or crutches, with weight bearing as determined by the stability of the intraoperatively. In patients with stable internal fixation, touchdown weight bearing of the affected extremity was allowed. In patients with comminuted fractures and with relatively unstable fixation, weight bearing is delayed until radiological evidence of fracture healing and a fracture brace may be needed. Day 8 to 10: Suture removed. Prophylactic antibiotics were used in all patients. By 6 weeks, if $X$ rays showed signs of union progression, increased weight bearing was allowed. By 12 weeks, with further evidence of radiological consolidation, full weight bearing was allowed. All the patients were followed up. With each follow up, clinical and radiological examinations were performed at 6 weeks, 12 weeks, 24 weeks and thereafter once in three months. Femoral shaft fractures are serious injuries that generally result in short- term disability and pain but also have a high risk of longer- term deformity and disability.

\section{Results}

Functional results were graded based on the classification system for the results of treatment by Thoresen B.O., et al., $(1985)^{7}$ Majority of patients were in the age group ranging from 18-60 years, youngest being 18, eldest being 60 years mean age being 33 years. Out of 37 patients 35 were male and 2 were females. In the present study all the patients had a history of Road Traffic Accident. Twenty-seven cases were right sided and eight cases were left sided fracture shaft of femur. In the present study 23 were transverse fracture, 4 were oblique fracture, 1 was spiral and 9 were communited fractures. In our study three patient had associated tibial shaft fracture on the same side. One patient had ipsilateral degloving injury over the calf region. One patient had ipsilateral patella fracture and proximal third undisplaced tibial fracture. One patient had ipsilateral fracture humerus and 1 patient had fracture both bones of right forearm with lateral malleoli fracture. Average duration between trauma and surgery in our study was 6 days. Most common nail length was $400 \mathrm{~mm}$. Most common diameter nail used was $10 \mathrm{~mm}$ and static locking done primarily in all patients. Partial weight bearing with crutches/walker was started on an average between postoperative day 2 to day 5.9 patient with significant communition were advised delayed weight bearing. Mean time of union was 16 week in this study. Time to union ranged from $10-24$ weeks. All patients had full range of motion at the hip and knee joint. Valgus angulation of 5 degrees was observed in 2 patients and varus.

Malalignment of 5 degrees was observed in 2 patient. No rotational deformities. patients had a shortening of $1.5 \mathrm{cms}, 2$ 
patient had shortening of $1 \mathrm{~cm}$, and 1 patient had shortening of $2 \mathrm{~cm}$. There were no cases of nonunion noted in our study. Superficial infection noted on 6th day in 2 patients that resolved with antibiotics. No instances of deep infectio were no instances of nail breakage in our study, nor any instance of breakage of locking bolts. 2 patients complained of sporadic knee pain persisting after fracture union.

Table 1: Distribution of patients according to the age

\begin{tabular}{|c|c|c|}
\hline Age(years) & No. of patients & Percentage (\%) \\
\hline$<40$ & 32 & 86 \\
\hline$>40$ & 5 & 14 \\
\hline
\end{tabular}

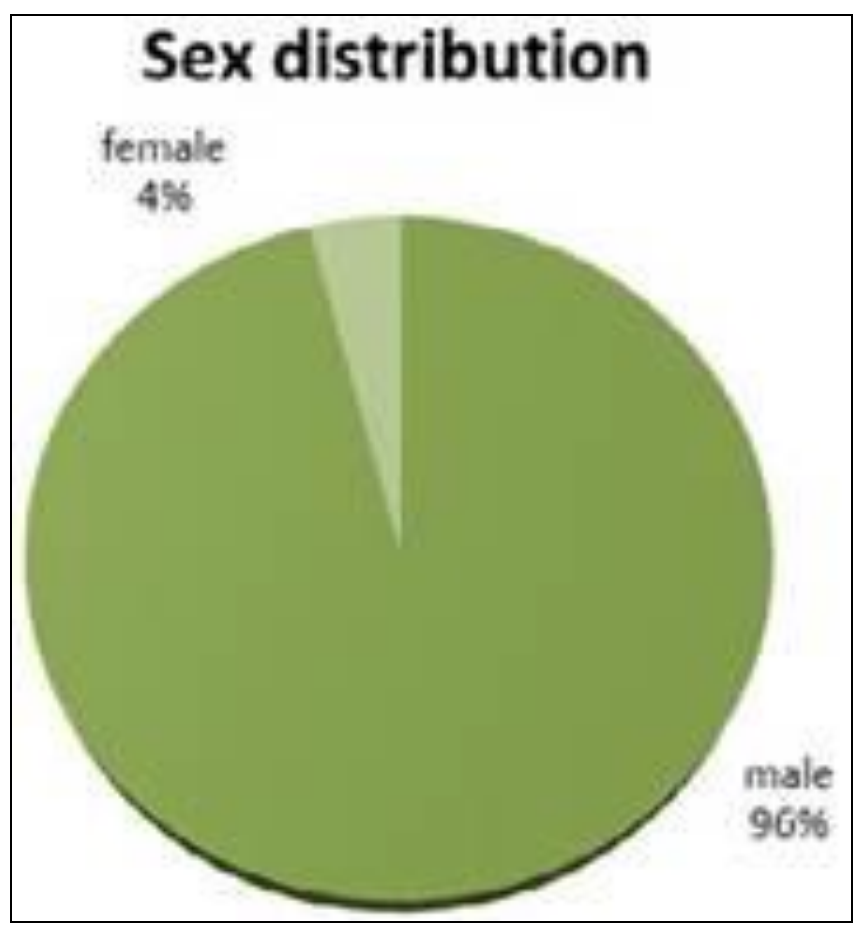

Fig 1: Distribution of patients according to the sex

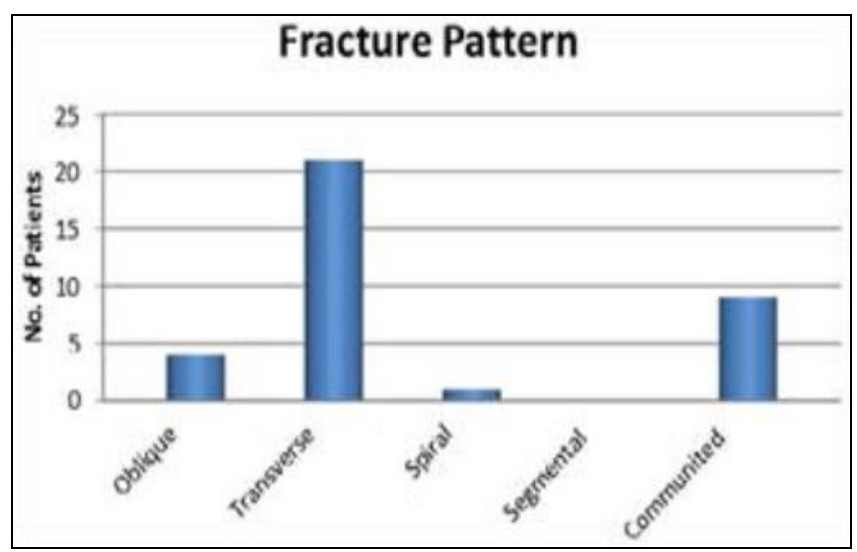

Fig 2: Fracture pattern in patients

Table 2: Distribution of patients according to Associated Injuries

\begin{tabular}{|c|c|c|}
\hline Associated injuries & $\begin{array}{c}\text { No of } \\
\text { patients }\end{array}$ & $\begin{array}{c}\text { Percentage } \\
(\mathbf{\%})\end{array}$ \\
\hline Ipsilateral tibial shaft fracture & 3 & 8 \\
\hline Ipsilateral tibial proximal third fracture & 1 & 3 \\
\hline Patella fracture & 1 & 3 \\
\hline Humerus Fracture & 1 & 3 \\
\hline Lateral malleoli fracture & 1 & 3 \\
\hline Fracture both bones forearm & 1 & 3 \\
\hline
\end{tabular}

Table 3: Distribution of patients according to Postoperative
Mobilization

\begin{tabular}{|c|c|c|}
\hline $\begin{array}{c}\text { No. of days } \\
\text { postoperatively }\end{array}$ & $\begin{array}{c}\text { Number of } \\
\text { patients }\end{array}$ & $\begin{array}{c}\text { Percentage } \\
(\mathbf{\%})\end{array}$ \\
\hline $2-5$ & 28 & 75 \\
\hline $6-10$ & - & - \\
\hline $10-15$ & 5 & 14 \\
\hline $15-20$ & 4 & 11 \\
\hline
\end{tabular}

Table 4: Limb length discrepancy

\begin{tabular}{|c|c|c|}
\hline $\begin{array}{c}\text { Limb length } \\
\text { discrepancy }\end{array}$ & $\begin{array}{c}\text { Number of } \\
\text { patients }\end{array}$ & $\begin{array}{c}\text { Percentage } \\
(\mathbf{\%})\end{array}$ \\
\hline$<1$ & 32 & 86 \\
\hline$<1.5$ & 2 & 6 \\
\hline 2 or More & 2 & 6 \\
\hline & 1 & 2 \\
\hline
\end{tabular}

Table 5: Assessment of functional results according to Thorensen

\begin{tabular}{|c|c|c|}
\hline Results & Number of patients & Percentage (\%) \\
\hline Excellent & 33 & 89 \\
\hline Good & 4 & 11 \\
\hline Fair & 0 & 0 \\
\hline Poor & 0 & 0 \\
\hline
\end{tabular}

\section{Discussion}

Intramedullary interlocking nailing has been proved to be an effective method among the available methods of Treatment for femoral shaft fractures in adults. Internal fixation of fractures of the femoral shaft has gained widespread acceptance as implants and technology have improved. The rationale for internal fixation is that it restores the anatomical alignment and allows early mobilization of the patient and limb. Studies have shown that the mean age of femoral fractures are between 20-35 years. In the study of Wiss et al. ${ }^{[8]}$ mean age was 29 years. Study of Thoresen (7) of 48 cases of femoral shaft fractures stated a mean age of 28 years. In most of the studies and in ours too the incidence was significantly higher in males. (33 males and 2 females). Mode of injury was road traffic accidents which was compatible to the other study in literature. In the study of Johnson et al. ${ }^{[9]}$ right side was predominantly involved in the study of Wiss et al. ${ }^{[8]}$ of communited fractures right side was predominantly involved. In our study right sided involvement was higher than the left. In the study of Thoresen et al. ${ }^{[7]}$ communited fractures were the commonest followed by the transverse and then the spiral pattern. In the study of Wiss et al. ${ }^{[8]}$ communited fractures predominated. In our study the commonest fracture seen was the transverse variety followed by oblique and then the spiral type. Since femoral fractures most often are caused by high velocity injuries associated fractures are not uncommon. We had a ipsilateral tibial shaft fracture in 3 patients, ipsilateral proximal third tibial fracture in 1 patient, patella fracture in 1 patient, humerus fracture in 1 patient, lateral malleoli fracture 1 patient and fracture of both bones of forearm in 1 patient. Patients were operated between 3-7 days after trauma, average duration being 6 days. All cases were operated under spinal anaesthesia with pt supine and positioned on the fracture table. There was some difficulty in gaining access to the piriform fossa in a couple of obese pts in the supine position but adduction of the limb facilitated the procedure. Commonest length and the diameter of the nail used was $400 \mathrm{~mm}$ and $10 \mathrm{~mm}$ respectively followed by $380 \times 10 \mathrm{~mm}$ and $360 \times 10 \mathrm{~mm}$ nail. This in contrast to the western literature where most of the nails used is of a larger diameter (13 and $14 \mathrm{~mm})$. In the study of Donald Wiss, ${ }^{[8]}$ average blood loss amounted to $470 \mathrm{ml} I n$ our study the 
average blood loss was $200 \mathrm{ml}$. Time to union of a fracture was defined as time from injury to full weight bearing and healing of the fracture characterized by bridging callus seen on two radiographs with different projections. In the study of Wiss et al. ${ }^{[8]}$ union was obtained at an average of 26 weeks. In the study of Thorensen et al. ${ }^{[7]}$ of 48 cases of femoral fractures mean time to union was 16 weeks. In our study time to union

ranged from 10 weeks to 24 weeks with an average of 16 weeks. Complications of nailing range from infections, malalignment, shortening, nonunion and failure of the implant. In the study of Wiss et al. ${ }^{[8]}$ the infection rate after closed nailing was $0.9 \%, 11.5 \%$ lengthening and $3.5 \%$ shortening. In study of Thoresen et al. ${ }^{[7]}, 6.25 \%$ had varus malalignment, $2 \%$ had valgus malalignment, $2 \%$ had internal rotation and $4 \%$ had external rotation deformity. In the study of Christie et al. ${ }^{[11]} 0.8 \%$ had superficial infection, $1-6 \%$ had non union, $0.8 \%$ had external rotation and $1.6 \%$ had delayed union. In our study there were no cases of nonunion, valgus malalignment of 5 degrees in 2 patients with distal third fracture, varus malalignment of $5^{\circ}$ in 2 patients, shortening of $>1.5 \mathrm{~cm}$ was seen in 2 patient and $1 \mathrm{~cm}$ in 2 patients and $2 \mathrm{cms}$ in 1 patient. Superficial infection in 2 patient that resolved with antibiotics. There were no instances of deep infection. Sporadic pain in the knee persisting after union after the fracture seen in 4 patients. Out of 35 patients according to the Thorensen scoring system 31 patients had excellent results 4 patients had good results. Duration of surgery ranged from 80 min -160 min with a mean of 90 min. Partial weight bearing was started at an average of 4 days and full weight bearing at mean of 13 weeks. Time to union ranged from 10-24 weeks with a mean of 16 weeks. We had our share of complications. Superficial infection was present in 2 patients that subsided with antibiotics. no cases of deep infection noted. No cases of non-union noted, valgus malalignment seen in 2 patient of 5 degrees. Varus mal alignment 5 degree seen in 2 patients. Shortening was noted in 4 patients, 2 had a shortening of 1 $\mathrm{cm}, 2$ had shortening of $1.5 \mathrm{~cm}$ and 1 had shortening of $2 \mathrm{cms}$. All patients had a complete range of motion at the knee at union. Hip movements were full range in all patients. No cases of implant failure were noted. Out of 35 patients according to the Thorensen scoring system7 patients had excellent results 4 patients had good results. Many centres in the United States and Europe have reported the safety and efficacy of fixation of femoral fractures in children and adolescents by flexible intramedullary nail. Heinrich et al. conducted a study on the 78 diaphyseal femur fractures stabilized with flexible intramedullary nails ${ }^{[12]}$.

\section{Conclusion}

Closed intramedullary nailing is an efficient method and does not expose the patient to an undue risk of infection or nonunion. It also helps in rapid union by means of preserving hematoma and limited soft tissue exposure. There is also no risk of limb length discrepancy and the angulation and rotational malalignment are within the acceptable limits. Interlocking intramedullary nailing is a very effective and successful method of definitive primary treatment, in most types of fractures of the shaft of the femur. Closed nailing is preferred over open nailing, due to its faster rate of healing.

\section{References}

1. Bucholz RW, Adam J. Fracture of shaft of femur, chapter 41, Robert W. Bucholz and James D. Heckman ed. Rockwood and Green's Fractures in Adult, Philadelphia:
Lippincott Williams and Wilkins 2001;2(5):1683-1730.

2. White AP, Wood G. Fractures of lower extremity; chapter 51, S. Terry Canal ed, Campbell's operative orthopaedics, New York: Mosby 2003;3(10):2825-2859.

3. Bhandari M, Guyatt GH, Khera V, Kulkami AV, Sprague S, Schemitsch EH. Operative management of lower extremity fractures in patents with head injuries. Clin Orthop 2003;407:187-98.

4. Boyer ML, Haidukewych GJ, Torchia ME. Intramedullary fixation of diaphyseal femoral fractures in elderly patients: analysis of outcomes and complications. Am J Orthop 2003;3291:42-5.

5. Zlowodzki M, Cole PA, Kregor PJ. Intramedullary nailing in elderly patients. Orthopedics 2004;27(6):545562.

6. Maniscalco P, Urgelli S, Rivera F, Bertone C, Lazzeroni L. The CLOS MB intramedullary naU for the treatment of pathological femoral shaft lesions. Acta Biomed Ateneo Parmense 2002;73(1-2):7-10.

7. Thorensen BO- Intramedullary nailing of femoral fractures- report of 48 cases 1985;67A:1313-1320.

8. Wiss DA, Chrlstopher H, Fleming, Joel M, Matta, Couglas Clark. Comminuted and Rotationally Unstable Fractures of the Femur treated with an Interlocking nai! 1986;212:35-47.

9. Johnson KD, Johnston BWC, Parker B. Comminuted femoral shaft fractures: Treatment by roller traction, cerclage wires and an intramedullry nail or an interlocking nail. J Bone and Joint Surg 1984; 66A:1222.

10. Wiss DA, Fleming CH, Malta JM, Clark D. Communited and rotationally unstable fractures treated with interlocking nail 1986;212;35-47.

11. Christie JC, Court-Brown AWG, Kinninmonth CR, Howie. Intramedullary locking Nails in The Management of Femoral Shaft Fractures J. Bone and Joint Surg. March 1988;70-B:206-210.

12. Heinrich SD, Drvaric DM, Karr K, Macevan GD. The operative stabilisation of the pediatric diaphyseal femur fractures with flexible intramedullary nails: A Prospective analysis. J Pediatr Orthop 1994;14:501-7. 